\title{
Identidades cultural e turística de São Miguel do Gostoso, Rio Grande do Norte (RN), Brasil
}

\author{
Cultural and Tourist identities from Miguel do Gostoso, Rio Grande do Norte \\ (RN), Brazil
}

\author{
Marcelo da Silva Taveira (TAVEIRA, M. da S.)
}

\begin{abstract}
RESUMO - Trata-se de uma discussão teórica a respeito dos conceitos de identidades cultural e turística, que também apresenta dados empíricos coletados por meio de pesquisa de campo pertinente a estudos no âmbito das ciências sociais e humanas, realizados nos anos de 2014 e 2015. No texto se aborda a relação turismo e comunidades de praia, em São Miguel do Gostoso (Rio Grande do Norte/RN, Brasil), importante destino turístico do litoral potiguar, cujos principais segmentos de mercado são: turismo de sol e praia e turismo de aventura. O cenário das relações socioculturais entre as populações anfitriã (comunidades de praia) e visitantes, revelou-se ao longo da pesquisa e percebeu-se quais os elementos que compunham as identidades do destino (percepção do turista) e da população local (dimensão sociocultural). Assim, neste artigo se retrata por meio de dados empíricos e arguições teórico-metodológicas, o conjunto de elementos culturais que traduziram as identidades, imbricadas em relações capitalistas, simbólicas, socioculturais, políticas e ambientais de tal processo.
\end{abstract}

Palavras-chave: Turismo; Identidade Cultural; Identidade Turística; São Miguel do Gostoso.

ABSTRACT - This is a theoretical discussion on the concepts of cultural and tourist identities, which also presents empirical data collected through field research related to studies in the ambit if social and human sciences, conducted in 2014 and 2015. In the text is approached the relationship between tourism and beach communities in São Miguel do Gostoso (Rio Grande do Norte / RN, Brazil), important tourist destination on the coast, which the main market segments are: sun and beach tourism and adventure tourism. The scenario of socio-cultural relationships between the host populations (beach communities) and visitors was revealed during the research and it was realized what were the elements that made the identities of the destination (tourist perception) and the local population (socio-cultural dimension). Thus, in this article is portrayed through empirical data and theoretical and methodological argumentation, the set of cultural elements that translated the identities, imbricated in capitalist, symbolic, sociocultural, political and environmental relations of this process.

Key words: Tourism; Cultural Identity; Tourist Identity; São Miguel do Gostoso.

\footnotetext{
* Formação: Graduação em Turismo pela Universidade Federal do Rio Grande do Norte (UFRN), Especialização em Meio Ambiente e Políticas Públicas (UFRN), Mestrado em Geografia (UFRN), Doutorado em Ciências Sociais (UFRN). Atividade profissional: Professor do Curso de Turismo da UFRN/Campus Currais Novos. Coordenador do Grupo de Pesquisa Turismo, Sociedade \& Território da UFRN. Endereço físico para correspondência: Rua da Campina, 140, Condomínio Verano de Ponta Negra, Torre A, ap. 2103, Ponta Negra. CEP: 50090-480 - Natal - Rio Grande do Norte (RN/Brasil). Email: marceloturismo@yahoo.com.br
} 


\section{INTRODUÇÃO}

O turismo, além de ser uma atividade econômica, também é um fenômeno sociocultural e, como tal, é construído, historicamente, pela ação dos sujeitos sociais e agentes econômicos por meio de processos capitalistas que evoluem no decorrer dos anos, sofrendo as intempéries globais e influenciando as particularidades locais. Portanto, as relações capitalistas produzidas na sociedade são também de natureza dialética, como são os discursos teóricos e a realidade empírica do turismo.

A relação dialética e de interdependência entre produção e consumo, remonta-se ao atual contexto da atividade turística que é potencializada nos destinos de "Sol e Praia" do litoral brasileiro, em que a dinâmica de produção e o consumo do espaço produzem e reproduzem a essência do próprio sistema capitalista de produção, e, por conseguinte, o modelo de desenvolvimento socioeconômico fortalecido pelo turismo, alicerçado nos moldes dos princípios fordistas de produção e do consumo de massa (diminuição do tempo de produção, otimização dos custos de produção, produção em série, rápida inserção do produto no mercado e alto consumo) em espaços requalificados para a manutenção da atividade econômica em questão.

A relação entre turismo e espaço no município de São Miguel do Gostoso, localizado no litoral do Rio Grande do Norte (RN/Brasil), tem como principal cenário o segmento de "turismo de sol e praia" (TAVEIRA, 2015), resultado de um produto globalizado e fruto das relações econômicas e de poder, baseado no padrão hegemônico e lucrativo da exploração de atividades de lazer para fins turísticos em espaços, em que a presença dos atrativos naturais (o sol, o mar, a paisagem, os ventos e etc.) tem relevância social e econômica. Sendo assim, tais elementos apresentam-se como condição sine qua non para que a produção e o consumo do turismo e desse espaço se ramifiquem e atendam aos anseios dos mercados capitalistas na sociedade contemporânea.

Para aprofundar a discussão, se utiliza de Lefebvre (2008) que faz um contraponto sobre os efeitos construtivos e benéficos do turismo, pois, para ele, é fundamental elucidar o caráter de consumo do espaço e dos lugares pela atividade turística, fazendo a seguinte reflexão: 
Estranho percurso, dizemos: a natureza entra para o valor de troca e para a mercadoria, é comprada e vendida. Os lazeres comercializados, industrializados, organizados institucionalmente, destroem essa "naturalidade" da qual as pessoas se ocupam a fim de traficá-la e trafegar por ela. A "natureza", ou aquilo que é tido como tal, aquilo que dela sobrevive, torna-se o gueto dos lazeres, o lugar separado do gozo, a aposentadoria da “criatividade" (LEFEBVRE, 2008, p. 117).

Não distante do pensamento de Lefebvre, Rodrigues (2000) afirma de forma contundente que o turismo por ser uma atividade econômica que enfatiza a produção e o consumo dos espaços, não é autossustentada, tampouco sustentável, como também defendem vários autores das ciências sociais e humanas (LEMOS, 2001; ALMEIDA, 2003; CARLOS, 1996) que afirmam que o turismo como as demais atividades econômicas não é sustentável, pois produz e consome o espaço e as riquezas a todo o tempo, o tempo todo, sendo um processo intrínseco a todas as atividades produtivas, dentre elas, o turismo.

Com o crescimento e a consolidação da sociedade capitalista pós-guerra, fundamentados pela formação da sociedade industrial que possui raízes no continente europeu ainda no século XVIII, difundiram-se diversos processos que culminaram em conquistas do ponto de vista social nos séculos subsequentes, dentre elas: o tempo dedicado às atividades de lazer e a realização de viagens turísticas (TAVEIRA, 2015). Nesse contexto, os países periféricos não ficaram à margem desse processo, iniciando, mesmo que de forma embrionária, o desenvolvimento da atividade turística nos moldes capitalistas de produção e reprodução do capital, a qual se propagou por meio do segmento de turismo de sol e praia em escala global, principalmente em países litorâneos.

Nessa nova atmosfera alimentada pelo avanço do capitalismo foi construída, gradativamente, a ideia de que o turismo internacional significaria a geração de riquezas, trabalho, crescimento econômico e desenvolvimento social para as localidades receptoras (sobretudo nos países subdesenvolvidos), com destaque para as divisas econômicas geradas pelo capital estrangeiro reproduzido em ambientes litorâneos e responsável pela exploração da atividade turística voltada para o consumo de "sol e praia".

A necessidade de compreender as implicações da atividade turística em comunidades de praia, fundamenta-se na dimensão econômica e social que o litoral 
marítimo conquistou desde os meados do século $\mathrm{XX}$, mais precisamente no período do Pós-Guerra (depois das duas grandes guerras mundiais que ocorreram em 1914/1918 e 1939/1945, respectivamente). Após o término dessas guerras, o mar passou a ter outros usos e funcionalidades além daquelas convencionais ou tradicionais como: a navegação, a pesca e a exploração mineral, predominantemente (TAVEIRA, 2015).

A partir dos meados do século XX, o mar ganha novas conotações no contexto brasileiro, especialmente no que diz respeito às práticas de lazer (segunda-residência e turismo). Nesse sentido, a questão-problema formulada para iniciar a presente discussão foi a seguinte: quais os elementos identitários aferidos à população residente e ao turismo do destino São Miguel do Gostoso?

O objetivo central dessa análise foi o de apresentar elementos culturais que fizeram parte do processo de construção da identidade dos moradores e do destino turístico São Miguel do Gostoso.

No que concerne ao plano metodológico, aborda-se técnicas de pesquisa que se fundamentaram no levantamento preliminar de referências bibliográficas sobre o objeto estudado, porém, essas foram consubstanciadas pelo caráter empírico de observações que foram realizadas in loco e por meio de relatos coletados que foram evidenciados a partir de contato direto junto à população residente e turistas (nacionais e estrangeiros), atores sociais contemplados nas entrevistas. Dessa maneira, considera-se que se garantiu maior precisão e confiabilidade nos dados gerados pelas pesquisas de campo para que, posteriormente, fossem realizadas as devidas análises de natureza qualiquanti a respeito da realidade turística de São Miguel do Gostoso.

A amostra da pesquisa referente à população residente foi selecionada por meio de cálculo estatístico com base nos setores censitários habitados de São Miguel do Gostoso, sendo que a fonte de dados padrão utilizada foi o Censo 2010 do Instituto Brasileiro de Geografia e Estatística (IBGE), cuja população do município (8.670 habitantes ${ }^{1}$ ) foi fator determinante para a definição da amostragem estratificada (IBGE, 2010).

Durante a realização do processo em questão, foi necessário ter ciência em relação a algumas informações como o número da população residente nos núcleos de

\footnotetext{
${ }^{1}$ A população residente de acordo com o Censo 2010 do IBGE era de 8.670 habitantes, mas a estimava populacional para o ano de 2015 foi de 9.427 moradores, aproximadamente, segundo dados da Diretoria de Pesquisas - DPE e Coordenação de População e Indicadores Sociais - COPIS (IBGE, 2015).
} 
praia de São Miguel do Gostoso de acordo com os setores censitários do IBGE. Essas informações foram fatores chave para a definição do tamanho da amostra a ser coletada e estão presentes na fórmula geral de amostragem para populações conhecidas, apresentada a seguir:

$$
n=\frac{N \cdot Z^{2} \cdot p \cdot(1-p)}{Z^{2} \cdot p \cdot(1-p)+e^{2} \cdot(N-1)}
$$

A equação (1) foi utilizada para obter o valor amostral (n) desejado para populações finitas, onde o tamanho $(\mathrm{N})$ é conhecido. O erro amostral (e) representa a diferença máxima que pode ser apresentada entre o resultado da pesquisa e o resultado real, quanto menor o erro amostral maior será o tamanho da amostra. O nível de confiança $(1-\alpha)$ representa a probabilidade de o erro amostral efetivo ser inferior ao erro amostral admitido pela pesquisa, esse nível de confiança quando padronizado na distribuição normal apresenta um valor representado na fórmula pela letra (Z), quanto maior o grau de confiança maior será o tamanho amostral, por fim, existe a probabilidade real do evento ocorrer (p), como já explicitado pelo nome, informa quais as chances comprovadas do fato estudado ser real (este item nem sempre pode ser aplicado durante uma amostragem, nestes casos, utiliza-se o valor de 0,5).

São Miguel do Gostoso possui 16 setores censitários habitados, que são unidades territoriais de coleta das operações censitárias, com limites físicos identificados, em áreas contínuas e respeitando a divisão político-administrativa do Brasil (IBGE, 2010). Destes 16 setores, 5 pertencendo ao perímetro urbano central do município foram unificados para amostragem e entrevista (agrupados no núcleo urbano denominado Sede) e os demais setores foram representados pelas comunidades rurais (IBGE, 2010).

O trabalho de campo e de amostragem levou em consideração 12 estratos (Sede com agrupamentos urbanos e 11 distritos rurais), dos quais foi estimada, proporcionalmente, uma quantidade amostral para ser entrevistada na pesquisa de campo. Utilizando-se de um erro amostral máximo de 5\% e nível de confiança a 95\%, obtidos pela equação (1) que correspondeu a uma amostra representativa para com o município totalizando 393 indivíduos que estariam distribuídos proporcionalmente entre os 12 estratos selecionados, incluindo a sede municipal, conforme dados da tabela 1 a seguir: 


\begin{tabular}{lcc}
\hline \multicolumn{2}{c}{ TABELA 1 - SÃO MIGUEL DO GOSTOSO - ALOCAÇÃO AMOSTRAL NOS ESTRATOS } \\
\hline \multicolumn{1}{c}{ ESTRATOS (COMUNIDADES) } & TAMANHO & PERCENTUAL \\
Sede & AMOSTRAL & AMOSTRAL \\
Comunidade Morro do Martins & 256 & $65,14 \%$ \\
Comunidade Antônio Conselheiro & 34 & $8,65 \%$ \\
Comunidade Baixinha dos França & 33 & $8,40 \%$ \\
Comunidade Novo Horizonte & 14 & $3,56 \%$ \\
Comunidade Canto da Ilha de Cima & 11 & $2,80 \%$ \\
Comunidade Cruzamento & 10 & $2,54 \%$ \\
Comunidade Reduto & 8 & $2,04 \%$ \\
Comunidade Tabua & 7 & $1,78 \%$ \\
Comunidade Praia do Marco & 6 & $1,53 \%$ \\
Comunidade Arizona & 6 & $1,53 \%$ \\
Comunidade Paraíso & 4 & $1,02 \%$ \\
Total & 4 & $1,02 \%$ \\
\hline
\end{tabular}

FONTE: TAVEIRA, M. S. (2015).

A soma global dos percentuais dos 12 estratos contemplados para a realização do levantamento dos dados empíricos chegou a 100\%, o que representou o tamanho total da amostra.

O processo de coleta de dados foi realizado por meio da aplicação de formulários de pesquisa com perguntas abertas e fechadas, previamente estruturados que foram respondidos pelas populações residente e flutuante (visitantes/turistas) do município.

Conforme os resultados da amostragem realizada foram aplicados 393 formulários direcionados aos residentes da sede municipal e das 11 comunidades rurais. Em relação aos turistas, como já citado anteriormente, não foi possível a obtenção de dados referentes à população média presente no município em determinado período de tempo, uma vez que não foram encontrados estudos de demanda turística ou dados sistematizados por parte da gestão pública e das empresas prestadoras de serviços turísticos. Desse modo, os formulários foram aplicados livremente, sem uma definição amostral fixada, obtendo-se assim, 72 entrevistas; sendo 54 oriundas da demanda doméstica e 18 de turistas estrangeiros.

Nessa direção, as entrevistas junto aos atores sociais, anteriormente mencionados, foram também analisadas, qualitativamente, por meio das técnicas de análise do conteúdo, que foi a maneira mais adequada para a análise e interpretações 
dos dados definidas aqui como o método de investigação e análise mais adequado. A análise de conteúdo na visão de Bardin (2011, p. 48):

[...] é um conjunto de técnicas de análise de comunicações visando obter por procedimentos sistemáticos e objetivos de descrição do conteúdo das mensagens indicadas (quantitativos ou não) que permitem a inferência de conhecimentos relativos às condições de produção/recepção (variáveis inferidas) dessas mensagens.

A análise de conteúdo se apresenta no campo das ciências humanas e sociais em que "o ponto de partida é a mensagem, seja ela verbal (oral ou escrita), gestual, silenciosa, figurativa, documental ou diretamente provocada" (FRANCO, 2012, p. 12).

Franco (2012) aborda nas discussões sobre análise de conteúdo questões de domínios teórico e prático do emprego adequado desse tipo de metodologia em que a concepção, a análise e a interpretação das mensagens são passos ou processos a serem seguidos e que no caminhar desses processos, deve-se levar em consideração a contextualização como um princípio básico para garantir a relevância dos sentidos atribuídos às mensagens.

Diante dos cenários teórico e empírico, os quais alicerçaram esse estudo, tais metodologias tiveram por finalidade assegurar o tratamento adequado das informações oriundas de pesquisas de campo e investigações documentais, bem como, permitir que o conteúdo dessas informações elucidassem questões para análises mais aprofundadas e contextualizadas da realidade pesquisada, e dos discursos narrados pelos diversos atores sociais que participaram ativamente da construção desse processo.

\section{SÃO MIGUEL DO GOSTOSO: “A CIDADE DOS VENTOS”}

A configuração espacial de São Miguel do Gostoso é desenhada pela ação dos ventos alísios e posição geográfica que influi nos demais elementos da geografia desse destino turístico e contribui para a formação ambiental e a geomorfologia do lugar (TAVEIRA, 2015). Nesse sentido, apresentam-se alguns aspectos e fatores necessários para a melhor compreensão das características físicas e espaciais dessa região litorânea do Rio Grande do Norte. 
De acordo com o Instituto de Desenvolvimento Sustentável e Meio Ambiente (IDEMA) São Miguel do Gostoso é um dos 167 municípios do Rio Grande do Norte e está localizado a $102 \mathrm{~km}$ da capital do Estado (ver mapa 1), na Mesorregião Leste Potiguar e Microrregião Litoral Nordeste, cuja área territorial total é de $343,750 \mathrm{~km}^{2}$. Seus limites territoriais são: ao Norte, o Oceano Atlântico; ao Sul e Leste, o município de Touros; e ao Oeste, os municípios potiguares de Pedra Grande e Parazinho.

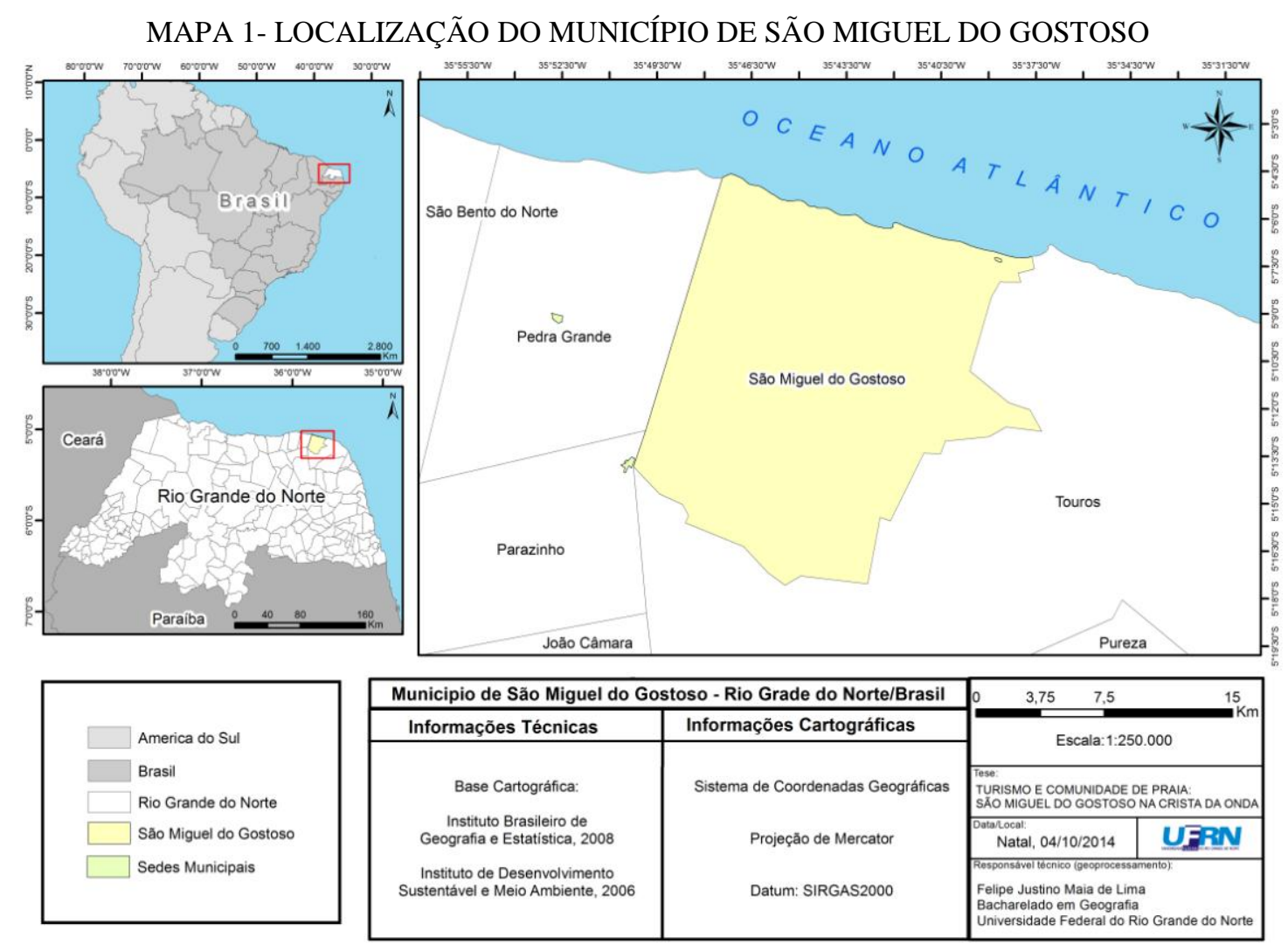

FONTE: Taveira (2015) a partir de IBGE.

Com localização privilegiada no litoral potiguar, região conhecida, popularmente como a "esquina do Brasil" (TAVEIRA, 2015). São Miguel do Gostoso possui as seguintes coordenadas geográficas: latitude $=5^{\circ} 07^{\prime} 29^{\prime}$ Sul e longitude $=35^{\circ}$ 38' 21" Oeste (IBGE, 2010). Tais coordenadas contribuem para a presença de ventos (alísios) fortes e contínuos nessa porção do litoral potiguar, o que tem contribuído de forma determinante para a prática de esportes náuticos e atividades de aventura nas praias desse município (TAVEIRA, 2015).

A força e a presença dos ventos motivaram a visitação dos primeiros esportistas e amantes de atividades de aventura junto à natureza, em São Miguel do Gostoso que 
tem como principal acesso a Rodovia Estadual RN 221 (via de acesso que interliga a BR 101 à sede municipal de São Miguel do Gostoso) (TAVEIRA, 2015).

Durante o ano o período de maior presença e ação dos ventos na região ocorre entre os meses de setembro e março, o que justifica a extensa temporada de alta estação turística existente no município, que possui aproximadamente 6 meses de duração ao longo do ano (TAVEIRA, 2015).

São Miguel do Gostoso se inseriu no turismo a partir dos anos de 1990 como um novo "paraíso" turístico, paralelamente à Praia da Pipa² (que encontra na vanguarda do turismo potiguar como destino de sol e praia e de ecoturismo), cujos bens naturais (sol, praias, vegetação, paisagem e os ventos) formam o conjunto de atrativos apropriados pelo mercado para fins turísticos.

A Praia de Tourinhos é um dos espaços mais visitados de São Miguel do Gostoso para fins recreativos, especialmente para o banho e a contemplação da natureza. Conhecida pelo conjunto cênico e harmonioso ao meio ambiente comumente é denominada pelos turistas como um "paraíso" preservado para o descanso e a visitação (TAVEIRA, 2015).

\section{SÃO MIGUEL DO GOSTOSO: DE RECANTO DE PESCADORES ì “CRISTA DA ONDA” DO TURISMO POTIGUAR}

Ao longo do processo histórico de construção socioeconômico e cultural de São Miguel do Gostoso, surgiram duas importantes comunidades, Reduto e Tabua (assentamentos rurais) e, por conseguinte, a estruturação do núcleo urbano mais povoado da região, ou seja, a sede ou centro do município, que abriga nos dias correntes, cerca de $70 \%$ da população local, aproximadamente, onde também trabalha e reside a maioria dos pescadores do lugar (TAVEIRA, 2015).

A Colônia de Pescadores (Z-34) e a Associação dos Pescadores do município estão localizadas na área mais urbanizada de São Miguel do Gostoso. A intensa rotina dos moradores em relação ao trabalho junto ao mar, meio de sobrevivência e de

\footnotetext{
${ }^{2}$ Pipa apesar de ter ganhado mais projeção e estrutura turística depois dos anos de 1990, foi "descoberta" por surfistas na década de 1980 e nos anos de 1970 era um núcleo de segunda residência (lugar de veraneio) (TAVEIRA, 2015).
} 
atividades agregadas do cotidiano de natureza econômica (artesanato) e cultural (crenças, lendas e mitos), é a expressão máxima da relação homem-mar, pois todas as dimensões da vida são atreladas e giram em torno dos elementos naturais, especialmente, o mar (TAVEIRA, 2015).

A pesca artesanal é uma atividade produtiva que faz parte da economia de São Miguel de Gostoso e responde pela principal fonte de renda de dezenas de famílias, além de preservar essa cultura, que é peculiar ao "homem do mar", ao pescador na arte desse ofício (TAVEIRA, 2015).

São Miguel do Gostoso possui várias singularidades do ponto de vista histórico, cultural, social, econômico, político e ambiental, que não são "histórias de pescador", mas revelam muito sobre os acontecimentos que contribuíram para o surgimento e a formação sociocultural do lugar e, consequentemente, da identidade cultural das pessoas que ali vivem.

Uma de suas principais singularidades é o nome da cidade, São Miguel do Gostoso, não propriamente por causa do santo católico, mas pelo substantivo "Gostoso" (status de nome próprio) que era um "apelido" de um personagem local muito conhecido no tempo que viveu na região, que teve acrescentado ao nome o "sobrenome" Gostoso. Anos depois, o Gostoso que surgiu como substantivo próprio transformou-se em adjetivo, agregando qualidade, prazer, satisfação e emoção a São Miguel do Gostoso, mesmo quando ainda era uma pequena vila de pescadores (TAVEIRA, 2015).

Assim, "Gostoso" foi incorporado ao nome do município e ao imaginário social dos moradores e visitantes. E foi partir dos anos de 1990, com a chegada ainda incipiente do turismo, que o nome "Gostoso" se transformou em sinônimo de belezas naturais, de "paraíso", de um lugar com praias paradidáticas, de difícil acesso, reduto de esportes náuticos, tranquilidade e um povo alegre e hospitaleiro (TAVEIRA, 2015).

O gentílico de quem nasce em São Miguel do Gostoso é "Micaelense de Touros" (IBGE, 2010), mas a população nativa se denomina de "gostosenses", ou, simplesmente, "gostosos", como é mais comum entre os residentes. Trata-se de mais um fato curioso, mas que se tornou uma das marcas desse que pode ser considerado como um importante destino turístico no cenário contemporâneo.

“Gostoso" é sinônimo para quase tudo na cidade, além de ser o gentílico extraoficial foi o nome dado ao primeiro meio de hospedagem da cidade, a Pousada do 
Gostoso, inaugurada no final da década de 1980, bem como restaurantes, eventos, passeios turísticos e outras atividades de lazer (TAVEIRA, 2015).

"Gostoso" reflete o clima turístico e de hospitalidade predominante na cidade, uma vez que, o turismo é a principal fonte de renda dos empresários locais e de muitos moradores que trabalham nessa atividade, embora não seja a maior atividade econômica empregadora de recursos humanos (TAVEIRA, 2015), conforme mostra o gráfico a seguir:

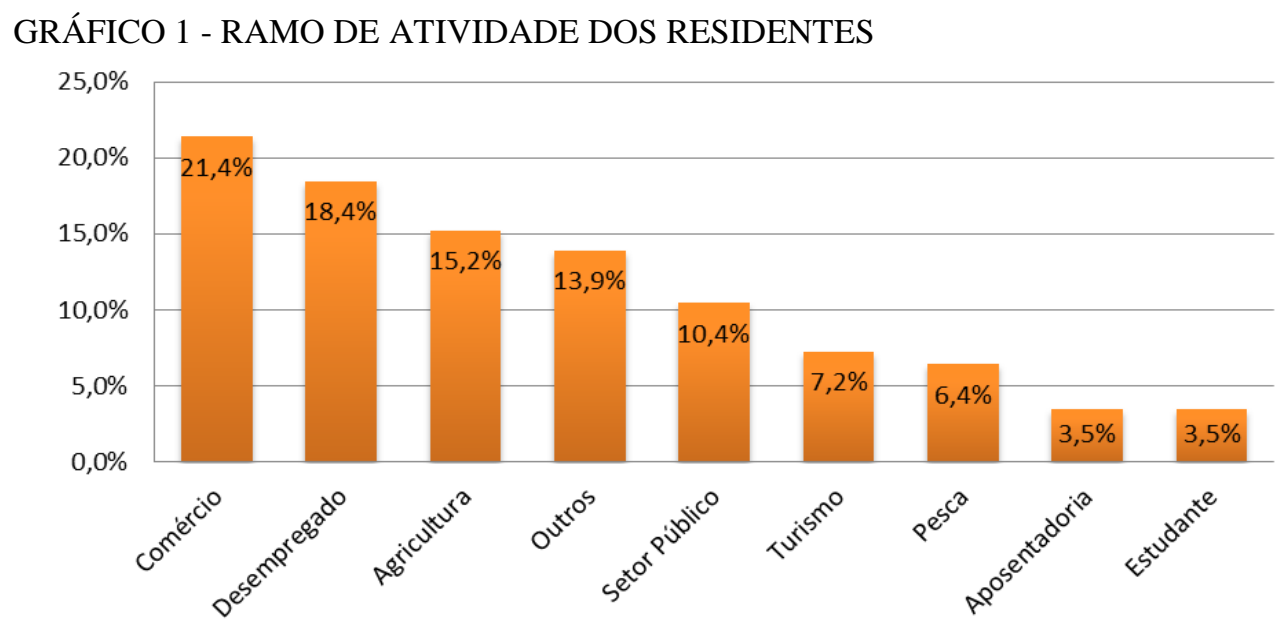

FONTE: Taveira (2015).

As atividades tradicionais (agricultura e pesca) com forte presença no município são voltadas à subsistência da população residente, ou seja, não são comerciais como ocorre em outras realidades brasileiras. E mesmo com o turismo intensificado na última década, os produtos oriundos da agricultura e da pesca permanecem com baixa capilaridade na região, sendo comercializados em pequena escala junto ao comércio local, incluindo, nesse nicho, algumas pousadas e restaurantes.

São Miguel do Gostoso deu início à atividade turística por meio do mix de marketing e de suas estratégias comerciais. Os primeiros visitantes que procuraram a região estavam em busca da tranquilidade, descanso e das belezas naturais. Posteriormente, a descoberta desses bens naturais da região (mar e ventos constantes) tornaram-se propícios para a prática de esportes de aventura como o kitesurf ${ }^{3}$ e o windsurf $^{4}$ (TAVEIRA, 2015).

\footnotetext{
${ }^{3}$ Junção de duas palavras inglesas: kite, que significa pipa e surf, que quer dizer navegar. Na prática, o kitesurfista utiliza uma prancha fixada aos pés e uma pipa inflável (semelhante a um parapente)
} 
Assim, "Gostoso" começou a ganhar notoriedade nacional e internacional no segmento de esportes náuticos de aventura e despertou a atração de visitantes e esportistas de várias partes do mundo, o que ocasionou, em curto tempo, um boom turístico na cidade e novas configurações socioespaciais no destino (TAVEIRA, 2015).

No contexto das configurações socioespaciais, ambientais, políticas e econômicas de São Miguel do Gostoso são desenhadas por meio de fatores políticosinstitucionais e capitalistas, que foram impulsionadas pelo processo pujante do mundo globalizado, em que na visão de Carlos (1996, p. 15): "a globalização materializa-se concretamente no lugar, aqui se lê/percebe/entende o mundo moderno em suas múltiplas dimensões, numa perspectiva mais ampla, o que significa dizer que no lugar se vive, se realiza o cotidiano e é aí que ganha expressão mundial”.

Também compõe o cenário das configurações socioespaciais, a prática do windsurf (IMAGEM 1) que se posiciona estar entre as principais modalidades de esportes de aventura praticados no litoral do município, por moradores locais e, especialmente por turistas, com destaque para os estrangeiros que vêm ao Brasil, especificamente para experienciar esse tipo de esporte náutico no cenário de São Miguel do Gostoso (TAVEIRA, 2015):

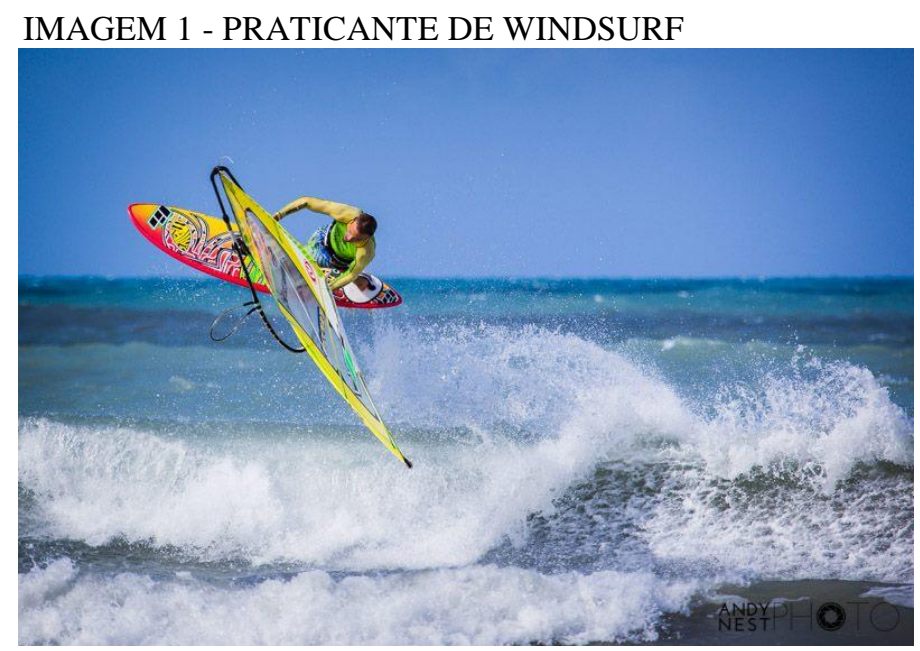

FONTE: Taveira (2015).

possibilitando deslizar sobre a superfície da água e, ao mesmo tempo, alçar voos que se traduzem em movimentos singulares. Ou seja, o vento é o motor, e o grande fator de emoção do kitesurf. O cenário pode ser o mar, um rio, um lago, uma represa. (ABETA, 2014).

${ }^{4}$ Ventos e ondas são os principais ingredientes dessa atividade que uniu a prancha do surf à vela do iatismo. No Brasil, a atividade começou a ser praticada no final dos anos 1970. (ABETA, 2014). 
Os esportes de aventura que têm como pano de fundo além dos ventos, outros elementos da natureza como o sol e o mar, apresentam-se no contexto atual como uma verdadeira coqueluche para a atração de turistas nacionais e internacionais.

As atividades de esportes de aventura praticadas nas praias de São Miguel do Gostoso necessitam da ação dos ventos alísios como força motriz para a realização de diversas manobras "radicais" ou não, que são pertinentes a essa modalidade esportiva (IMAGEM 2). Desse modo, o kitesurf assim como o windsurf, é o esporte náutico que mais atrai os visitantes à região, que vêm em busca de lazer, emoção e entretenimento junto à natureza. A adrenalina e a sensação de liberdade são potencializadas por esse tipo de esporte e traduz-se em elementos fundamentais para esse nicho de mercado, bem como, para os praticantes (TAVEIRA, 2015):

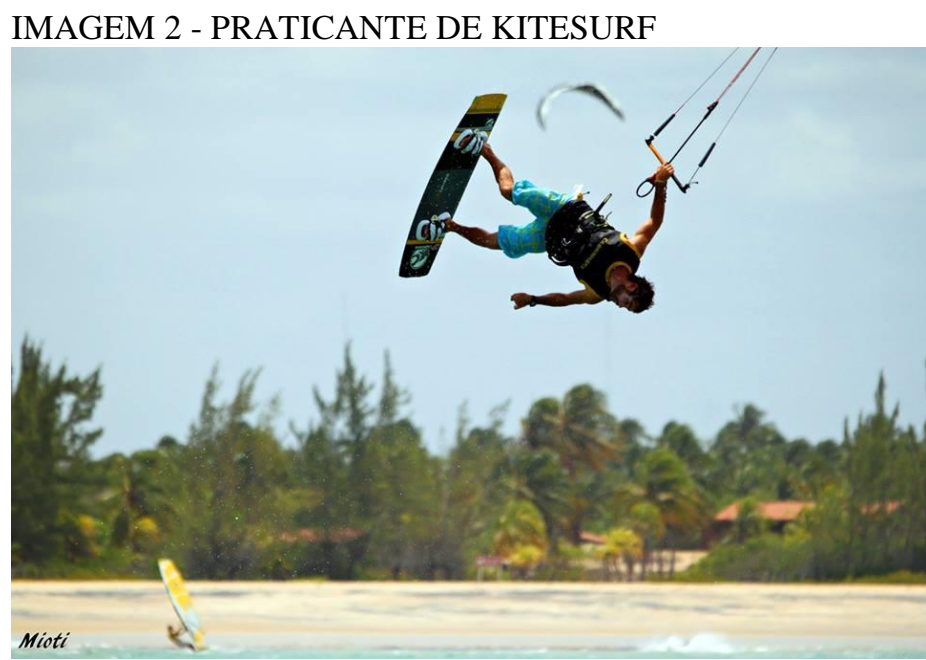

FONTE: Taveira (2015).

A partir do ano de 2010 outras atividades de aventura também são praticadas com maior frequência pelos visitantes de São Miguel do Gostoso, como: Stand Up Paddle $^{5}$, cicloturismo e trilhas ecológicas são alguns dos exemplos. As atividades têm influenciado o aumento do fluxo turístico diversificando a oferta de atividades desenvolvidas na natureza (TAVEIRA, 2015).

Porém, não foram os esportes náuticos os principais responsáveis pela chegada dos primeiros turistas a São Miguel do Gostoso e sim a paisagem que foi apropriada,

\footnotetext{
${ }^{5}$ A chegada de novos equipamentos e técnicas de canoagem ao país tem proporcionado o surgimento de novas atividades. O Stand Up Paddle, por exemplo, é uma atividade que mescla canoagem com surfe, em que o turista rema em pé em cima de uma prancha. Esta atividade tem atraído adeptos no país e pode ser praticada no mar, em lagos e rios de águas calmas (ABETA, 2015).
} 
historicamente para fins turísticos. No contexto paisagístico da região, a paisagem se posiciona no campo do simbólico, como o principal atrativo turístico local, contemplando elementos da natureza como: o mar, a geomorfologia, o clima, as cores e conteúdos concretos e subjetivos, além de abrigar um coqueiral que é uma das identidades da cultura praieira e da atividade econômica existente no lugar (plantio e colheita do coco, fruto dessa árvore de origem indefinida, que gera discussões geográficas e históricas entre os pesquisadores) (TAVEIRA, 2015).

Portanto, pode-se dizer que o ponto de partida para apropriação do espaço para fins turísticos foi a paisagem, porém, ao ser apropriada e passar ao longo dos anos pelo processo de turistificação, apresenta-se no contexto contemporâneo como um patrimônio histórico, social, político, ambiental, econômico e turístico.

\section{IDENTIDADES CULTURAL E TURÍSTICA DE SÃO MIGUEL DO GOSTOSO: OLHARES DO RESIDENTE E DO TURISTA}

O Tejo é mais belo que o rio que corre pela minha aldeia, Mas o Tejo não é mais belo que o rio que corre pela minha aldeia, Porque o Tejo não é o rio que corre pela minha aldeia. O Rio da Minha Aldeia: Alberto Caeiro

Para o poeta português Fernando Pessoa, o rio Tejo e o rio que corre na aldeia possuem conteúdos diferentes ou seriam identidades distintas? Não é fácil decifrar a essência filosófica e real do pensamento do grande poeta, mas toma-se essa reflexão como ponto de partida para discussão sobre identidade cultural e o mosaico da vida cotidiana em comunidade.

A identidade cultural pode ser atrelada a uma sociedade, comunidade, povo ou grupo social, até mesmo, ao indivíduo em nível micro de compreensão dos aspectos socioculturais, da posição e papel perante aos demais atores que integram determinado grupo de pessoas. Em São Miguel do Gostoso, a identidade cultural é plural e dinâmica, tendo sido influenciada pelos aspectos culturais e econômicos do lugar, com destaque para o turismo, atividade econômica que se consolida ao passar dos anos e que promove efeitos diversos junto à população local (TAVEIRA, 2015). 
Castells (1999) ao teorizar sobre a construção do "poder da identidade" para compreender o conteúdo da organização dos movimentos sociais, também leva em consideração os aspectos pertinentes à composição e formação de uma comunidade. Segundo esse autor, as comunidades são construídas a partir dos interesses e anseios dos membros, o que faz dessas fontes específicas de identidades.

As identidades podem nascer da intenção em manter o status quo, ou de resistir aos processos dominantes e às efemeridades do mundo globalizado, ou ainda de buscar a transformação da estrutura social. Em todas elas existem processos de identidade, objetivos e interesses em comum, a participação em prol deste objetivo, o sentimento de pertencimento oriundo da identidade existente (CASTELLS, 1999).

Ainda de acordo com Castells (1999) a identidade cultural é um dos elementos de sociabilidade, da preservação das tradições, hábitos e costumes, bem como das relações socioculturais coletivas existentes nas comunidades. Por isso, o conceito de identidade cultural será discutido no transcorrer desse trabalho a fim de qualificar, teoricamente, as informações sobre as comunidades de praia pesquisadas. Castells aborda a questão da identidade ou identidades, como um núcleo resistente à homogeneização e que pode ser semente de mudanças socioculturais.

As identidades culturais são construídas em consonância com as mudanças sociais e das novidades culturais emergentes. Essa afirmação condiz com o que se observa em relação às implicações do fenômeno turístico em comunidades que preservam atividades "tradicionais", a exemplo da pesca artesanal, presente no litoral potiguar, que se depara com a lógica do turismo e, muitas vezes, deixa-se influenciar por inovações relativas a aspectos culturais e econômicos.

Hall (2014) em pesquisas sobre a mudança estrutural que fragmentou os estudos sobre identidades culturais de classe, sexualidade, etnia, raça e de nacionalidade, notou que as identidades tradicionais ou velhas identidades, que sempre fizeram parte do mundo social, estão em declínio.

Para Hall (2014) as identidades culturais se materializavam em localizações sólidas, nas quais os indivíduos se encaixavam socialmente, mas que na pósmodernidade as fronteiras foram redefinidas ou são menos definidas, o que proporcionou no indivíduo uma verdadeira "crise de identidade". 
As mudanças, as crises econômicas e sociais, os avanços no campo da tecnologia e da informação são alguns dos ingredientes que provocam a tal crise de identidade enfatizada por Hall (2014), o que reflete as relações do indivíduo com o ambiente vivido, marcado por um mix e conexões do local-global-local ou global-localglobal, um conjunto complexo de relações interativas e concretas que implica no contexto e no cotidiano vivenciado pelos indivíduos.

A identidade é um elemento fundamental de identificação com alguma coisa, comunidade, sociedade, cultura, gosto, estilo, grupo, modo de vida e/ou outros fatores da vida coletiva, o que imprime ao homem (ser) uma essência social indispensável ao existir e se relacionar com os pares e com a própria vida. Sendo assim, alguns autores discutem sobre esse tema, o que é de grande relevância para o entendimento da realidade encontrada em São Miguel do Gostoso, especialmente, sobre os elementos que compõem a identidade cultural dos moradores e da cidade como destino turístico.

Claval (1995) por meio de estudos sobre a geografia cultural, afirma que a cultura é um campo comum para o conjunto das ciências humanas, sendo uma mediação entre o homem e a natureza. Para ele, a identidade cultural se diferencia em relação "a origem comum, o desejo de adequar-se às práticas de um grupo e a construção da pessoa que repousa na articulação exercida de todos os aspectos da vida centrados na cultura" (CLAVAL, 1995, p. 146). A partir dessa análise, entende-se que a identidade é múltipla, complexa e não padronizada, uma vez que, ela se modifica, é mutável e transitória de acordo com o contexto e a realidade de cada sociedade, grupo ou comunidade.

A identidade também pode ser entendida sob o prisma da dinâmica sociocultural local, sendo "oriunda de uma assimilação que travam entre si o homem e o grupo particularizado no lugar de vivência, onde ocorrem práticas e interações que se assentam na relação sociocultural na relação local" (SILVA, 2007, p. 169).

De acordo com Silva (2007) se percebe que a identidade faz parte do contexto e da relação sociocultural no mundo de vivências do homem na perspectiva individual e coletiva. Sendo as práticas de interação a formatação das dinâmicas socioculturais em nível local.

Castells (1999, p. 79) ao refletir sobre identidades em nível territorial pelo viés da comunidade, comenta: 
O provável argumento dos autores comunitaristas, coerente com minha própria observação intelectual, é que as pessoas resistem ao processo de individualização e atomização, tendendo a agrupar-se em organizações comunitárias que, ao longo do tempo, geram um sentimento de pertença e, em última análise, em muitos casos, uma identidade cultural, comunal.

Na visão de Castells (1999), para que as organizações comunitárias e a construção de uma identidade cultural se concretizem, é necessário um processo de mobilização social, em que as pessoas participem de movimentos urbanos, não, necessariamente, revolucionários, pelos quais são revelados os interesses comuns ao grupo. E nessa direção, a vida é de alguma forma, compartilhada, e um novo significado de grupo poderá ser constituído.

Para o autor, as comunidades, como por exemplo, as pesquisadas em São Miguel do Gostoso, são construídas por meio da ação coletiva e são preservadas por meio da memória coletiva, o que constituem fontes, a força motriz de identidades. Segundo Castells (1999, p. 84) "essas identidades, no entanto, consistem em relações defensivas contra as condições impostas pela desordem global e pelas transformações, incontroláveis e em ritmo acelerado". As comunidades, nesse contexto, edificam abrigos, porém não constroem paraísos.

A identidade também foi pensada sob o prisma da poesia. É que se pode constatar nos versos poéticos de Mia Couto:

Preciso ser um outro para ser eu mesmo Sou grão de rocha Sou o vento que a desgasta

Sou pólen sem inseto

Sou areia sustentando o sexo das árvores

Existo onde me desconheço aguardando pelo meu passado ansiando a esperança do futuro No mundo que combato morro no mundo por que luto nasço Identidade: Mia Couto.

De conteúdo, essencialmente poético, o fragmento textual passa a mensagem que a identidade é uma marca, um emblema pessoal, mas que somente transcende por 
meio do contato com o outro e com os eventos plurais do mundo, incluindo a memória do passado, o ensaio do presente e a abstração simbólica do futuro.

Em relação aos turistas entrevistados na pesquisa de campo, o olhar sobre a identidade cultural de São Miguel do Gostoso mostrou-se plural e sublime, que segundo Urry (1996, p. 16) "não existe um único olhar do turista enquanto tal. Ele varia de acordo com a sociedade, o grupo social e o período histórico". É com esta afirmação que se iniciou a discussão a respeito do olhar do turista sobre a identidade cultural desse destino turístico.

De acordo com Urry (1996) o olhar do turista é determinado pela situação vivenciada em dado momento histórico, é construído por meio de relações com o oposto (o residente, o sujeito não turista e suas atividades cotidianas ligadas ao trabalho e ao lar). Corroborou-se com o autor e defende-se que esse olhar sugere a existência de um conjunto de signos sociais e significados nos campos do simbólico e do real, que se expressam por meio de práticas turísticas desenvolvidas nos destinos de viagem, como acontece em São Miguel do Gostoso.

Nessa perspectiva, fazer turismo, viajar, tirar férias, são componentes de fenômenos sociais pertinentes ao campo do lazer que ganha cada vez mais forma e conteúdo na sociedade contemporânea, sendo produto e reflexo das relações capitalistas de poder e distinção social.

O turista é produto da condição humana e da vida social, é um fenômeno efêmero que dura por um tempo determinado, de acordo com o grau de fugacidade desse tempo e condição social. O turista não é um personagem, ele é um sujeito real, cujo conteúdo é de natureza relacional, pois depende da intensidade de capital cultural construído, historicamente, ao longo de sua existência em momentos que ele não está na condição de turista, mas que também é o afloramento dessa condição.

O olhar do turista é transitório, esporádico e, às vezes, alienado, dependendo da situação vivenciada e do nível cultural. Nesse caso, embora, o capital econômico seja determinante para a concretude da atividade turística, do ato de viajar, é o capital cultural que vai determinar o tipo, o conteúdo, a relação com as populações receptoras e com o destino visitado.

No caso de São Miguel do Gostoso, o turista motivado e inspirado para consumir as belezas naturais e, usufruir daquilo que determinou a sua ida ao destino, ou 
seja, o trinômio sol-praia-ventos, como foi constatado pela pesquisa de campo, muitas vezes, não estava conseguindo enxergar além das riquezas ambientais, cujo olhar está com foco no produto comercial (práticas de lazer e entretenimento) e não na experiência sociocultural local por meio do contato direto com os residentes, sua cultura, estilo de vida, costumes e hábitos, por exemplo.

Sendo o elemento cultural "hospitalidade", o maior atributo atribuído pelos entrevistados (turistas e moradores) à população residente de São Miguel do Gostoso, de acordo com a inversão do olhar, poderia estar atrelado apenas ao bom atendimento, à qualidade e à presteza na oferta dos serviços ao turista, não sendo consideradas outras características socioculturais como: povo hospitaleiro, acolhedor, alegre, feliz, simpático e outros elementos intrínsecos à hospitalidade da população residente. A relação turista-anfitrião é muito tênue e complexa, um reflexo das relações socioculturais construídas e da forma/conteúdo do olhar do turista sobre os demais atores sociais envolvidos no processo.

Perguntou-se durante a pesquisa in loco, para aproximadamente 400 moradores de São Miguel do Gostoso, a respeito da identidade cultural do lugar e dos moradores. E, apesar, da grande dificuldade da maioria, em definir ou descrever em apenas uma palavra ou frase algo que remetesse à identidade cultural e/ou às características culturais que representavam os moradores da cidade, as respostas mais frequentes tinham a ver com: povo acolhedor, trabalhador, humildade, alegria, simplicidade, simpatia, hospitalidade, agricultura, pesca, praia, festa de São João, artesanato (bordado denominado de labirinto), religiosidade, calmaria, sossego, tranquilidade, esportes (kitesurf e windsurf), a cultura popular (pastoril e boi de reis), gastronomia, pessoas receptivas, honestidade, solidariedade folclore, festejos e muitas outras.

Os elementos que remeteram à identidade cultural de São Miguel do Gostoso e dos moradores, que apareceram de forma predominante nas entrevistas foram: as praias e a pesca como as principais características identitárias da cidade; e a hospitalidade como a principal característica coletiva dos moradores, do povo que vive no lugar.

$\mathrm{Na}$ visão dos turistas nacionais e estrangeiros consultados, a identidade cultural da cidade foram os bens naturais, especialmente, a praia e os ventos, além dos esportes náuticos. E, no que diz respeito à identidade cultural do povo do lugar, a hospitalidade 
apareceu de forma expressiva, sendo a principal característica da população residente segundo os entrevistados.

Vale ressaltar que, como o turismo estava se concentrando apenas no perímetro urbano de São Miguel do Gostoso, o olhar do turista sobre o significado da identidade cultural da população residente e do próprio destino turístico, remeteu-se ao que foi percebido e vivenciado pelo turista, excluindo-se desse ponto de análise os elementos socioculturais e naturais existentes nas comunidades de praia, nos locais menos urbanizados (distritos, assentamentos e zonas rurais).

Portanto, entende-se que o conceito de identidade tem a ver com a alteridade em que a construção da identidade cultural deve ser compreendida e analisada, ou seja, como um processo histórico e socialmente, construída, sendo uma dinâmica interativa, contínua, plural e relacional de identidade e diferenciação das pessoas, individualmente ou por meio da coletividade, como constatado em São Miguel do Gostoso.

\section{CONSIDERAÇÕES FINAIS}

São Miguel do Gostoso, cidade construída, social e historicamente com valores tradicionais e com base na relação das pessoas com o mar e com a terra, transmuda-se para as relações com visitantes que têm o mar como espaço de lazer e não de trabalho como os residentes. $\mathrm{O}$ ambiente dos residentes formado de atrativos naturais que preserva as identidades vitais da cultura marítima e sertaneja insere a marca do turismo associada ao imaginário social de moradores e apropria-se do caminho do mar e da direção dos ventos.

Embora, a atividade pesqueira em São Miguel do Gostoso tenha notável relevância econômica e social, esse lugar teve formação histórico-social fundamentada por meio da expressiva tradição agrícola, por se tratar de um território, expansivamente rural, no qual predomina a produção agrária e o estilo de vida sertaneja, ou seja, residentes do litoral com tradição sertaneja, voltados para o cultivo e produção agrícola e à criação de animais de pequeno (pecuária de pequeno e médio porte).

São Miguel do Gostoso, além de abrigar praias destinadas às atividades diversificadas de lazer, também possui um conjunto de praias que desenvolve a pesca 
artesanal, atividades modernas como o turismo, a geração de energia eólica e as práticas de esportes de aventura. Todavia, esse destino turístico surgiu como uma pacata vila de pescadores, em que a pesca se apresentava como um dos elementos mais significativos da identidade cultural e a paisagem como a principal motivação e causa para o processo de turistificação que influenciou a transformação sociocultural do lugar, historicamente construída, passando de vila à cidade.

A identidade cultural de São Miguel do Gostoso atrelada aos elementos do mar é ampliada para turistas com o turismo de aventura de natureza náutica. No que concerne ao destino turístico "Gostoso", a identidade do lugar é expressão valorativa dos moradores que passa a hospitalidade para além dos elementos naturais que identifica a cidade. Na concepção dos turistas, em especial os estrangeiros, a identidade cultural da cidade foram os atributos naturais: praia e os ventos, associados aos esportes náuticos. E no que diz respeito à identidade cultural do povo do lugar, a hospitalidade expressou a principal marca da população residente.

Espera-se que este texto suscite novas reflexões e pesquisa a respeito do tema aqui abordado, pois a relação anfitrião-residente, como também a construção da identidade cultural das populações receptoras e dos destinos turísticos, especialmente, daqueles localizados no litoral brasileiro, apresenta-se como um desafio instigante no campo dos estudos e da produção do saber turístico.

\section{REFERÊNCIAS}

ABETA. ASSOCIAÇÃO BRASILEIRA DAS EMPRESAS DE ECOTURISMO E TURISMO DE AVENTURA. Atividades de Ecoturismo e Turismo de Aventura. Disponível em: <http://www.abeta.tur.br/index.php/atividades>. Acesso em: 23/11/2015.

ALMEIDA, M. G. Paradigmas do Turismo. Goiânia: Alternativa, 2003.

BARDIN, L. Análise de Conteúdo. São Paulo: Edições 70, 2011.

CARLOS, A. F. A. O Lugar no/do Mundo. São Paulo: Hucitec, 1996.

CASTELLS, M. O poder da identidade. (A era da informação: economia, sociedade e cultura, v. 2). São Paulo: Paz e Terra, 1999. 
CLAVAL, P. La géographie culturelle. Paris: Nathan, 1995.

COUTO, M. Raiz de Orvalho e outros poemas. Lisboa/Portugal: Editorial Caminho, 1999.

FRANCO, M. L. P. B. Análise de Conteúdo. 4. ed. Brasília: Liber Livro, 2012.

HALL, S. A identidade cultural na pós-modernidade. Rio de Janeiro: Lamparina, 2014.

IBGE - INSTITUTO BRASILEIRO DE GEOGRAFIA E ESTATÍSTICA. Censo 2010. Disponível em:

<http://www.cidades.ibge.gov.br/xtras/perfil.php?lang=\&codmun=241255\&search=riogrande-do-norte|sao-miguel-do-gostoso>. Acesso em: 23/11/2015.

IDEMA. INSTITUTO DE DESENVOLVIMENTO SUSTENTÁVEL E MEIO AMBIENTE DO RIO GRANDE DO NORTE. Perfil do Seu Município: São Miguel do Gostoso. Natal: IDEMA, 2008.

LEFEBVRE, H. O Direito à Cidade. 5. ed. São Paulo: Centauro, 2008.

LEMOS. A. I. G. de. Turismo: impactos socioambientais. 3. ed. São Paulo: Hucitec, 2001.

RODRIGUES, A. B. Turismo e desenvolvimento local. 3. ed. São Paulo: Hucitec, 2002a.

URRY, J. O olhar do turista - lazer e viagens nas sociedades contemporâneas. São Paulo: Studio Nobel, SESC, 1996.

TAVEIRA, M. da S. Turismo e comunidades de praia: São Miguel do Gostoso no caminho do mar e na direção dos ventos. Tese (Doutorado em Ciências Sociais). Natal, UFRN, 2015.

Recebido em: 18-03-2016.

Aprovado em: 17-04-2016. 